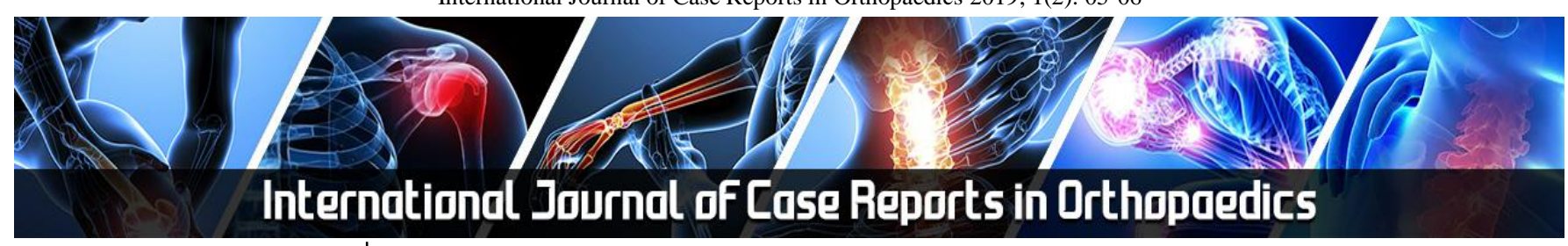

E-ISSN: 2707-8353 P-ISSN: 2707-8345 IJCRO 2019; 1(2): 05-06 Received: 10-05-2019 Accepted: 13-06-2019

Divesh Goyal

Department of Orthopaedics, Medanta Bone and Joint Institute, Gurgaon, Haryana, India
Corresponding Author: Divesh Goyal

Department of Orthopaedics, Medanta Bone and Joint Institute, Gurgaon, Haryana, India

\section{Isolated right capitate fracture- A case report and Review}

\section{Divesh Goyal}

DOI: https://doi.org/10.22271/27078345.2019.v1.i2a.8

\begin{abstract}
Capitate fracture is considered an uncommon injury to the carpal bones that comprises around $1.3 \%$ of all fractures of carpal bones. Most of these fractures are concomitant with other carpal lesions, predominantly the fracture of scaphoid. We reported a case of isolated right capitate fracture in 22 years old female patient.
\end{abstract}

Keywords: Capitate, fracture, Scaphoid

\section{Introduction}

Lower extremity stress fractures are common and are usually related to overtraining. However, this kind of injury is rare in the upper limbs and there are few reports in the literature regarding this trauma ${ }^{[1]}$. Scaphoid fractures usually occur in young adults after a fall on the outstretched arm resulting in acute dorsiflexion of the wrist. The patient presents with pain at the radial side of the wrist, tenderness on the snuffbox, pain on palpation of the scaphoid tubercle, and difficulties with range of motion. Radiographs are necessary to confirm the diagnosis, and sometimes a magnetic resonance imaging must be performed ${ }^{[2]}$. Capitate fracture is considered an uncommon injury to the carpal bones that comprises around $1.3 \%$ of all fractures of carpal bones ${ }^{[3]}$. Most of these fractures are concomitant with other carpal lesions, predominantly the fracture of scaphoid. Isolated fractures of the capitate are accounted for only $0.3 \%$ of carpal bone fractures. Harrigan first reported a case with such fracture in 1908. Dislocation of isolated fracture of capitate is very rare ${ }^{[4]}$.

Most capitate fractures occur in association with additional carpal injuries, particularly scaphoid fractures. Isolated fractures of the capitate account for only $0.3 \%$ of carpal injuries, and stress fractures are one form of this fracture ${ }^{[5]}$. We reported a case of isolated right capitate fracture in 22 years old female patient.

\section{Case Report}

A 22 years old female patient visited to the department with fractured right capitate bone since 1 week. Patient denied any history of trauma to the region in the past. General physical examination was normal. All vital signs were within normal range.

AP view, lateral radiographs and three-dimensional computed tomography $(\mathrm{CT})$ of the right wrist have revealed a minimally displaced fracture line located at the midcarpal aspect of the right capitate. A magnetic resonance imaging (MRI) scan showed subarticular capitate fracture in the midcarpal aspect with depression and diffuse bone marrow edema. There were small osteophytes in the capitate with irregularity of the midcarpal articular cartilage and a suspicious volar capito-hamate ligament injury. Based on the findings, we confirmed that patient suffered a stress fracture of the capitate with osteoarthritis of the midcarpal joint and an adjacent ligament injury. The patient underwent an arthroscopic debridement and multiple drillings using a drill and K-wire. The capitate subchondral fracture and synovial hypertrophy were confirmed during surgery. There were no complications, and the patient was able to resume her daily routine after two months. The prognosis was good.

\section{Discussion}

Isolated fracture of the capitate is rare and frequently associated with trauma, most commonly resulting from a fall on the palm with the wrist extended, axial load, or a direct blow over the dorsum of the wrist. Reports of capitate fractures commonly include Fenton's syndrome (concomitant fracture of both scaphoid and capitate), but only $0.3 \%$ of the 
fractures of the wrist are the isolated fracture of the capitate [6]. The isolated fracture of the capitate is uncommon because of its anatomic support; it is placed between the third and the fourth metacarpal bones the hamate, the lunate, the scaphoid, and the trapezoid and it is also protected from fractures because of its cuboidal morphology. Due to the intercarpal ligaments, most of its fractures remain dislocated. Isolated capitate fracture may be misdiagnosed because of the lack of clinical symptoms and it ambiguous radiographs. Bone scan, CT scan, and MRI have been recommended for these occult fractures ${ }^{[7]}$. We reported a case of isolated right capitate fracture in 22 years old female patient.

The capitate is often considered as the "keystone" of the carpus, not simply because of its central and prominent position in the wrist, but also because of its mechanical interactions with neighboring bones. Previous studies on wrist motion have provided information regarding the functional and mechanical significance of the capitate. According to the findings of these studies, the wrist has two degrees of freedom of motion - flexion-extension motion and radioulnar deviation - with two axes of rotation located within the head of the capitate where one is slightly more proximal than the other ${ }^{[8]}$.

Chronic repetitive dorsiflexion with axial compression of the wrist are frequently associated with injuries of the distal radial growth plate. This injury is typically seen on radiographs as a widened and irregular distal radius physis. Although wrist pain in gymnasts has been considered a "normal and direct consequence of the sport," the complaint of pain in these younger athletes must be carefully evaluated ${ }^{[9]}$.

In a recent study, a rotational motion around the axis has been shown to obliquely penetrate the head of the capitate in an almost radial extension/ulnoflexion plane of motion of the wrist. Rand et al. ${ }^{[10]}$ reported a case in motorbike rider, aged 27 years, who was involved in a motorcycle accident. He complained of right wrist pain, and wrist motion was considerably impaired. In the right wrist radiograph and CT scan, an isolated displaced capitate fracture was diagnosed. Open reduction was done under regional anaesthesia. After confirming the guide-wire's position and reduction of the fracture by imaging, authors applied a headless compression screw. After 24 months, the patient regained pain-free activity level with $90 \%$ of grip strength (in comparison with the contralateral wrist), with extension, flexion, radial deviation, ulnar deviation, supination, and pronation of $75^{\circ}$, $75^{\circ}, 15^{\circ}, 30^{\circ}, 80^{\circ}$, and $80^{\circ}$, respectively.

Albertsen et al. ${ }^{[11]}$ reported the case of a 20-year-old male who had a stress fracture of the capitate after serving as an honor guard in the military. Conventional radiographs confirmed that case. Authors also reviewed the carpal kinematics which possibly caused the stress fracture. Although stress fractures of the capitate are rare, they should also be accounted for with patients who perform repetitive motions of the wrist to a considerable extent.

\section{Conclusion}

Authors found that early diagnosis and open reduction of the displaced fragment in the treatment of such difficult fractures can lead to a successful outcome.

\section{References}

1. Hopkins SR, Ammann W. Isolated fractures of the capitate: use of nuclear medicine as an aid to diagnosis. Int J Sports Med. 1990; 11(4):312-4.

2. Amadio PC, Moran SL. Fractures of the carpal bones. In: Green DP, editor. Green's operative hand surgery. New York: Elsevier Churchill Livingstone, 2005.

3. Harrigan AH. XVII. Fracture of the Os Magnum. Ann Surg. 1908; 48(6):917-22.

4. Panagis JS, Gelberman RH, Taleisnik J, Baumgaertner M. The arterial anatomy of the human carpus. Part II: The intraosseous vascularity. J Hand Surg Am. 1983; 8(4):375-82.

5. Yoshihara M, Sakai A, Toba N, Okimoto N, Shimokobe T, Nakamura T. Nonunion of the isolated capitate waist fracture. J Orthopaed Sci. 2002; 7(5):578-80.

6. Fenton RL. The naviculo-capitate fracture syndrome. J Bone Joint Surg Am. 1956; 38-A(3):681-4.

7. Marcuzzi A, Ozben H, Russomando A, Petit A. Chronic transscaphoid, transcapitate perilunate fracture dislocation of the wrist: Fenton's syndrome. Chir Main. 2013; 32(2):100-3.

8. Guiral J, Gracia A, Diaz-Otero JM. Isolated fracture of the capitate with a volar dislocated fragment. Acta Orthop Belg. 1993; 59(4):406-8.

9. Calandruccio JH, Duncan SF. Isolated nondisplaced capitate waist fracture diagnosed by magnetic resonance imaging. J Hand Surg Am. 1999; 24(4):8569.

10. Rand JA, Linscheid RL, Dobyns JH. Capitate fractures: a long-term follow-up. Clin Orthop Relat Res. 1982; (165):209-16.

11. Albertsen J, Mencke S, Christensen L, Teisen H, Hjarbak J. Isolated capitate fracture diagnosed by computed tomography. Case report. Handchir Mikrochir Plast Chir. 1999; 31(2):79-81. 